\title{
Entrevista com Jacques Fux
}

Shirley de Souza Gomes Carreira ${ }^{1}$

Jacques Fux é graduado em matemática e mestre em ciência da computação pela UFMG, doutor e pós-doutor em literatura pela UFMG, pela Universidade de Lille 3 (França) e pela Unicamp, além de pesquisador visitante na Universidade de Harvard. Sua tese de doutorado, versão do livro Literatura e Matemática: Jorge Luis Borges, Georges Perec e o OULIPO (Perspectiva, 2016), recebeu em 2011 o Prêmio CAPES de melhor tese de Letras e Linguística do Brasil e foi finalista do Prêmio APCA de 2016. Antiterapias (Scriptum, 2012), seu romance de estreia, venceu o Prêmio São Paulo de Literatura 2013 e o manuscrito de Brochadas: confissões sexuais de um jovem escritor (Rocco, 2015), recebeu Menção Honrosa no Prêmio Cidade de Belo Horizonte. Foi finalista do Prêmio Barco a Vapor 2016. Publicou ainda Meshugá: um romance sobre a loucura, que saiu pela prestigiosa Editora José Olympio, e recebeu o Prêmio Manaus de Literatura 2016, e Nobel (José Olympio, 2018) em que realiza o sonho de todo escritor: ser laureado com um Nobel de Literatura. ${ }^{2}$

Soletras: Bem antes do lançamento de Antiterapias, quando eu era editora de outra revista, tive a oportunidade de conhecer o Jacques Fux acadêmico e crítico. Foi com alegria que acompanhei o lançamento do seu primeiro romance, vencedor do prêmio São Paulo de Literatura de 2013 para autores estreantes. Gostaria que comentasse como foi essa transição de acadêmico a escritor?

Jacques Fux: Como já dizia o Pessoa: "tenho em mim todos os sonhos do mundo". Quis e ainda quero ser professor numa grande instituição - por isso, além dos pósdoutorados, escrevi vários artigos científicos. Ainda coleciono outros sonhos: o de ser

\footnotetext{
${ }^{1}$ Shirley de Souza Gomes Carreira é Doutora em Literatura Comparada, Professora Adjunta do Departamento de Letras da Faculdade de Formação de Professores da UERJ, docente do Mestrado em Estudos Literários do Programa de Pós-Graduação em Letras e Linguística da UERJ, líder do grupo de pesquisa "Poéticas da diversidade", cadastrado no CNPq, e editora-chefe da revista Soletras. shirleysgcarr@gmail.com.

${ }^{2}$ Biografia disponível no site do autor: http://www.jacquesfux.com.br/biografia/
} 


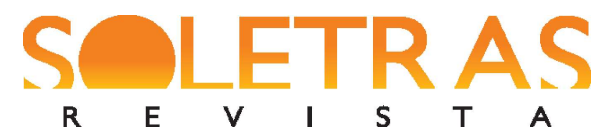

N. 38- 2019.2- SHIRLEY DE SOUZA GOMES CARREIRA JACQUES FUX

um violinista (comecei as aulas agora), correr uma maratona, voltar a disputar e ganhar campeonatos de squash... mas, claro, não dá para fazer tudo. Concentro-me, então, na minha vida de escritor - dando muitas escapadas -, porém convicto de que escrever ficção é o que mais gosto de fazer.

Soletras: Antiterapias foi saudado pela crítica como uma obra surpreendente, na medida em que mistura a história pessoal do narrador com inúmeras citações de grandes nomes da literatura, trechos de canções e menções a obras cinematográficas, além de abordar aspectos da cultura judaica que são desconhecidos do público em geral. Muitos críticos têm chamado a atenção para a sua erudição na área de Humanidades, uma vez que a sua formação inicial foi em Matemática e Ciências da Computação. Como é essa relação entre matemática e literatura? Eu li em algum lugar que você criou uma restrição matemática para utilizar citações em Antiterapias. Que tipo de restrição foi essa?

J. F.: O Antiterapias pode ser encarado como um romance de formação e, como um bom matemático-obsessivo-enciclopedista, tentei inserir no livro tudo que eu conhecia e que havia me tocado. A ideia 'teórica' do livro era fazer uso dos conceitos e estruturas oulipianas, borgeanas e matemáticas pesquisadas durante meu doutorado. Sim, inseri algumas regras. Uma delas é a das 'citações escondidas', o que chamo de 'plágio literário'. Tudo que acontece com narrador autoficcional tem que ter um 'par literário'. Assim, quando ele está falando de suas memórias e de seus amores, elas vão se misturando com as de Marcel, no Em busca do tempo perdido; quando ele está no banheiro fazendo 'ficção', quem está ao seu lado (soa bem estranho) é o Alexander Portnoy, do Complexo de Portnoy, de Philip Roth; quando ele está declarando suas animosidades, o narrador se vê junto a Dante colocando seus parentes e colegas nos círculos do inferno. Porém, apesar dessas regras percorrerem o livro, elas não podem saltar aos olhos - estão bem disfarçadas e embaralhadas. Um leitor conhecedor de algumas obras, vai saber que há ali uma "homenagem", uma releitura, e não um banal "plágio". 
Soletras: Antiterapias tem uma divisão em capitulos surpreendente e muito cativante. Para o público que ainda não leu o romance, cito alguns títulos de capítulos: "Astrofísico ou aquele que sonha as estrelas", "Falsário, ou aquele que perjura a memória", "Escritor, ou aquele que se agarra à invenção" e o título do posfácio: “Autor, ou aquele que plagia outra dor”. No posfácio, você diz: "O que eu queria era mergulhar nos meus sonhos. Nas minhas invenções. Em minhas lembranças falseadas. Encantadas. Passadas. Quem é o autor aqui? O autor está morto? Quem é esse eu que escreve o livro? O eu narrador e o eu autor". Antiterapias tem sido estudado pela academia como uma obra de autoficção. Como você se coloca ante esse rótulo?

J. F.: Também gosto muito da divisão e nomenclatura dos capítulos. São delicados, poéticos e até ingênuos. Como é meu primeiro livro, esse narrador-autor está se formando e desbravando um território ainda virgem e estranho. Gosto de chamar o livro de ficção, já que tem muito de mim e das minhas leituras e subversões. Recordar e recontar a vida é um ato fíccional, já que você pode dar foco a determinados momentos, esquecer de outros, reconstruir reminiscências, reinterpretar e ludibriar livremente.

Soletras: Em Antiterapias, o narrador diz: “Eu, que fui educado desde muito pequeno com os valores judaicos não os associava à religião. A religião não ensinava a forma como deveríamos tratar as pessoas, o meio ambiente, nós mesmos. Ensinava esse temor divino... e eu, que gostava e gosto dos valores humanos... admirava os valores judaicos. Não a religião, mas a cultura milenar". Quanto do autor há nesse posicionamento e até que ponto essa visão foi responsável pelo seu distanciamento da vertente literária judaico-brasileira tradicional?

J. F.: O autor-narrador de todos meus livros é sempre atormentado, estrangeiro e apaixonado pela questão judaica. Apesar de não ter crença, de não ter fé, de não seguir a religião de seus antepassados, ele se sente parte fundadora/fundamental dessa cultura milenar. O que o incomoda são os "legisladores da fé" - aqueles 'senhores' que se auto 


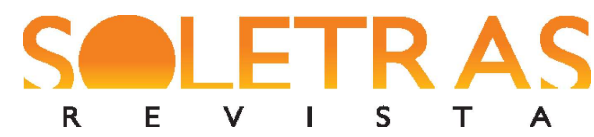

N. 38- 2019.2- SHIRLEY DE SOUZA GOMES CARREIRA JACQUES FUX

intitulam detentores do crivo que determina quem é e quem não é judeu. Meus personagens, em todos os livros, são judeus, porém judeus que exercem a questão central do judaísmo: questionar, colocar em xeque os dogmas, a relação de poder, a estrutura histórica e política vigente.

Soletras: Em Brochadas, o subtítulo da obra," confissões sexuais de um jovem escritor", indica uma leitura referencial, que é reforçada com o fato de o narrador também se chamar Jacques. Entretanto, você abre o livro com a epígrafe: "Tudo aqui é verdade, exceto o que não invento'. De certa forma, você já anuncia que está a brincar com o texto. A estrutura de Brochadas é muito interessante, porque você mistura pequenos textos com breves reflexões sobre o tema, relatos sobre figuras famosas que passaram pelo dissabor das brochadas, como Santo Agostinho, e mensagens que o narrador troca com ex-namoradas, comunicando seu plano de escrever o que ele mesmo denomina a "ilíada das brochadas" e, inclusive, usa o seu próprio e-mail. É uma obra que traz para o século XXI, atualizado, um recurso que era comum na literatura do século XVIII, ou seja, a estrutura epistolar. Tem o lado cômico da história também, que passa pelas respostas indignadas das ex-namoradas. Como foi a gênese desse romance? De onde surgiu essa ideia?

J. F.: Depois de ter ganhado o Prêmio São Paulo, quis escrever algo inédito e diferente, mesmo sabendo da dificuldade desse projeto. Falar sobre o fracasso, falha, sobre a impotência enquanto seres humanos não é um tema novo, mas talvez seja um tema recalcado, sobretudo na sociedade atual que vive das imagens do sucesso e da beleza expostas nas redes sociais. O 'Jacques' do Brochadas é um personagem que fracassa, que é impotente e que encara de frente (e mole) essa questão. Mas o livro é muito mais: expõe o lado machista do homem que atribui a mulher o seu fracasso sexual - e isso é discutido, já que as cartas das ex-namoradas dirigidas a esse degradado narradorpersonagem dão uma apunhalada a toda estrutura falocêntrica da humanidade -; também conta as brochadas literárias de grandes figuras - Freud, Fliess, Joyce, Borges, Santo Agostinho, Platão, Pessoa, Hemingway, entre outros -; aborda a questão dos 


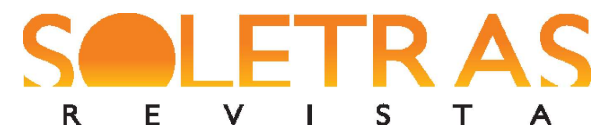

odores/essências - e como, por exemplo, alguns filósofos como Kant quiseram hierarquiza-la inferiormente para afastar o homem da sua animalidade. O livro, enfim, é uma enciclopédia-idílica das inúmeras facetas e possibilidade de uma brochada.

Soletras: De certo modo, seus livros exigem um leitor mais especializado, que seja capaz de perceber os diálogos intertextuais que você tece. Só o seu leitor potencial seria capaz de perceber, por exemplo, que os capitulos iniciais de Brochadas, intitulados "Tentativa de esgotamento do motivo das brochadas masculinas" $e$ "Tentativa de esgotamento do motivo das brochadas femininas”, são alusões claras ao livro de Perec, Tentativa de esgotamento de um lugar parisiense (2016). Como se dá esse diálogo com o texto do Perec?

J. F.: Acredito que a minha literatura tem vários níveis de leitura. Acredito que todos são capazes de ler e gostar (ou não) dos meus livros. Porém, se você é um leitor mais acostumado à literatura e conhecedor de algumas obras que me são caras, há uma possibilidade maior de 'desvendar' os enigmas, mistérios e as intertextualidades. O meu projeto é de um hipertexto em que o cânone está sempre ali - e sempre resgatado de forma séria e irônica - brincando com outras obras, com outras vidas e com muitos autores.

Soletras: Em Meshugá, você escolheu personagens que são judeus famosos, como Woody Allen e Sarah Kofman, e há uma relação muito estreita entre as histórias que o narrador conta e certas crenças sobre os judeus. Como você vê efetivamente essa relação?

J. F.: Meshugá busca recuperar os mitos e as lendas acercada loucura judaica. Várias teses alemãs versam sobre uma maior frequência de doenças mentais entre os judeus. De acordo com algumas teorias médicas e históricas, os judeus seriam mais propensos à loucura por serem incestuosos, tarados sexuais, obsessivos e espalharem doenças como sífilis. Fui atrás de 'personagens' reais que poderiam corroborar com essas teorias, 
visando ironizá-las e desconstruí-las. Encontrei personagens loucos como Bobby Fischer (enxadrista americano judeu que, apesar de ter sido um herói nacional ao ganhar o título mundial derrubando um jogador russo, ao fim da sua vida elogia os feitos catastróficos do 11 de setembro), Daniel Burros (judeu religioso na infância que, mais velho, cria o partido nazista americano e vira membro da KKK) e Otto Weininger (filósofo que se matou por possuir, segundo ele, as duas piores doenças: a judeidade e a homossexualidade). Porém, o que ocorreu ao escrever o livro, foi que esse narrador se envolveu com seus personagens e, assim como eles, introjetou o olhar odioso dos outros. O que emerge é o auto-ódio - a loucura é algo triste, dolorido e que acontece pela não compreensão de si e pelo antissemitismo histórico. Há também uma releitura e reinterpretação da História da Loucura e da História da Sexualidade, de Foucault

Soletras: Em sua visita à Faculdade de Formação de Professores da UERJ, em 2017, você encantou a plateia com o seu bom-humor e a sua habilidade para explorar a ironia como estratégia de abordagem dos temas. Nos livros anteriores, seus narradores eram muito próximos do que chamaríamos de anti-heróis, porém em Nobel o narrador é um escritor premiado. Claro que o humor e a ironia estão, como sempre, presentes no seu texto, mas há uma espécie de deslocamento aí, se o compararmos aos outros narradores que você criou. Gostaria que comentasse essa diferença.

J. F.: Acredito que o narrador do Antiterapias e do Brochadas, apesar de um senhor sério e literário, é bem leve e divertido. Ele se autodeprecia o tempo inteiro e, ao rir da própria desgraça, dos infortúnios e dos desencontros, dialogo com outros escritores como Philip Roth, Kafka, Bellow e Freud. O narrador de Meshugá é pesado, cruel diante da loucura e de suas dores e de seus personagens. Já o narrador de Nobel é sarcástico e irônico. Ele quer exorcizar os seus monstros e toda a essência do ser humano. Ele se incomoda com a política, com a vaidade, com os jogos de amizades e com os privilégios- mas ele sabe que só está ali, recebendo a maior láurea da literatura, por ter participado desse jogo. 
Soletras: Nobel alude ao conto "Um Relatório para a Academia", de Kafka, em que um macaco faz um discurso para os acadêmicos. Esse conto tem muito a dizer sobre a natureza humana, sobre a relação do homem com o sistema que o oprime e sufoca. Em seu livro, o narrador, agraciado com o Prêmio Nobel de Literatura, afirma que devotou à vida à transfiguração do seu eu, real e biográfico, em um eu ficcional e ventríloquo da memória e da obra dos outros. Essa rede intertextual é, com certeza, a base para o discurso do narrador e para o modo com que ele, por assim dizer, expõe negativamente o que nutre essa premiação máxima, mas sem abrir mão do seu direito ao prêmio. Qual a mensagem por trás do discurso?

J. F.: O discurso é um fechamento da tetralogia: que começou com o Antiterapias, em que o narrador diz que vai ganhar o Nobel, em seguida, passa pelas provações e fracassos ao ficar brocha e louco, até culminar com o recebimento do tão almejado prêmio. O discurso é um tratado sobre a pulsão que move o escritor. A mistura entre vida e obra, as idiossincrasias, as vergonhas, os recalques, os atos infames, grandiosos, benevolentes e perversos que movem os seres. Não há mitos, não há heróis, há apenas seres humanos - escritores ou não.

\section{Referências:}

FUX, Jacques. Antiterapias. Belo Horizonte, MG: Scriptum, 2012.

. Brochadas. Rio de Janeiro: Rocco, 2015.

. Literatura e Matemática: Jorge Luis Borges, Georges Perec e o OULIPO. São

Paulo: Perspectiva, 2016.

. Meshugá. Rio de Janeiro: José Olympio, 2016.

. Nobel. Rio de Janeiro: José Olympio, 2018.

KAFKA, Franz. Um relatório para uma Academia. In: Um médico rural. Trad.

Modesto Carone. 3. ed. São Paulo: Brasiliense, 1994, p. 57-67. 


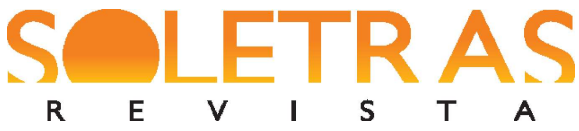

$\begin{array}{llllllll}\mathbf{R} & \mathbf{E} & \boldsymbol{V} & \mathbf{I} & \mathbf{S} & \mathbf{T} & \mathbf{A} & \text { N. 38-2019.2-SHIRLEY DE SOUZA GOMES CARREIRA }\end{array}$ JACQUES FUX

PEREC, Georges. Tentativa de esgotamento de um local parisiense. Traduzido por Ivo Barroso. Prefácio de Ricardo Luis Silva. São Paulo: G. Gili, 2016.

Entrevista concedida no dia 24 de abril de 2019. 